\title{
Short-Time Procedure for the Determination of Woehler and Fatigue Life Curves Using Mechanical, Thermal and Electrical Data *
}

\author{
Frank WALTHER ** and Dietmar EIFLER** \\ ${ }^{* *}$ University of Kaiserslautern, Institute of Materials Science and Engineering, \\ P.O. Box 3049, D-67653 Kaiserslautern, Germany \\ E-mail: walther@mv.uni-kl.de
}

\begin{abstract}
Mechanical stress-strain hysteresis, temperature and electrical resistance measurements were performed to characterize the fatigue behavior and to calculate the lifetime of metals under constant amplitude loading and random loading. Constant amplitude sequences were periodically inserted in random load tests to measure the plastic strain amplitude as well as the deformation-induced changes in specimen temperature and electrical resistance. These data are plotted versus the number of cycles for the fatigue assessment under random loading, similar as commonly practiced under constant amplitude loading. On the basis of Morrow and Basquin equations in generalized formulations, to be applicable for mechanical, thermal and electrical measurement techniques, a physically based fatigue life calculation method "PHYBAL" was developed. This new short-time procedure requires data of only three fatigue tests for a rapid and nevertheless precise determination of Woehler curves for constant amplitude loading or fatigue life curves for random loading.
\end{abstract}

Key words: Fatigue Life Calculation, Woehler Curve, Fatigue Life Curve, Random Loading, Metals, Stress-Strain Hysteresis Curves, Temperature and Electrical Resistance Measurements

\section{Introduction}

For reliable and cost-effective fatigue life calculations of metallic materials a systematic investigation of their fatigue behavior and a comprehensive understanding of the underlying fatigue mechanisms are mandatory. In general, the material response to cyclic mechanical loading is described by the plastic strain amplitude $\varepsilon_{\mathrm{a}, \mathrm{p}}$, determined in mechanical stress-strain hysteresis measurements ${ }^{(1)}$. Complementary temperature $\Delta \mathrm{T}^{(2)-(5)}$ and electrical resistance $\Delta \mathrm{R}^{(6)-(9)}$ measurements were performed with high resolution for a detailed characterization of the fatigue behavior of steels under constant amplitude loading and random loading. All mentioned physical quantities are directly influenced by deformation-induced changes in the microstructure of the bulk material and represent the actual fatigue state. Moreover, temperature and electrical resistance measurements can be applied to complex components under service loading to ensure economic and safe operation conditions of machines and plants. Related to a reference value of the virgin material state, the electrical resistance enables the detection of a proceeding fatigue damage in load-free inspections ${ }^{(10)-(11)}$. Apart from geometry, the electrical resistance depends on the electrical resistivity, which is strongly influenced by the load- and cycle-dependent defect structure and density of each individual material, e.g. dislocation density and arrangement, micro-cracks, pores and vacancies. Especially for material conditions and load amplitudes, 
which exhibit only small cyclic plastic deformation, temperature and electrical resistance measurements yield additional information about the actual fatigue behavior.

For the fatigue assessment under random loading a new test procedure was developed ${ }^{(10)(12)}$. Complex load spectra are combined with periodically inserted constant amplitude sequences for the determination of the plastic strain amplitude from closed $\sigma-\varepsilon$ hysteresis loops. Besides, within the short constant amplitude sequences temperature and electrical resistance data are obtained for the characterization of the fatigue behavior under random loading.

Due to elementary cross effects between the applied measurement techniques, plastic strain amplitude $\varepsilon_{\mathrm{a}, \mathrm{p}}$, temperature $\Delta \mathrm{T}$ and electrical resistance $\Delta \mathrm{R}$ data can be equivalently used for a physically based fatigue life calculation "PHYBAL" ${ }^{(10)-(12)}$ based on Morrow ${ }^{(13)}$ and Basquin ${ }^{(14)}$ equations in generalized formulations. This new short-time procedure requires data from only three fatigue tests for a precise calculation of Woehler (S-N) curves for constant amplitude loading or fatigue life curves for random loading. In comparison to the conventional experimental determination of theses curves, the application of "PHYBAL" leads to an enormous saving of time and costs.

\section{Nomenclature}

b fatigue strength exponent

$b_{M}$ fatigue strength exponent of generalized Basquin equation

f frequency

$I_{\text {const. }}$ direct current

K' cyclic hardening coefficient

$\mathrm{K}_{\mathrm{M}}{ }_{\mathrm{M}}$ cyclic hardening coefficient of generalized Morrow equation

M measured values $\varepsilon_{\mathrm{a}, \mathrm{p}}, \Delta \mathrm{T}$ or $\Delta \mathrm{R}$

n' cyclic hardening exponent

$\mathrm{n}_{\mathrm{M}}$ cyclic hardening exponent of generalized Morrow equation

$\mathrm{N}$ number of cycles

$\mathrm{N}^{*} \quad$ number of cycles under random loading

$\mathrm{N}_{\mathrm{f}} \quad$ number of cycles to failure

$\mathrm{N}_{\mathrm{f}}{ }^{*} \quad$ number of cycles to failure under random loading

$\mathrm{Q}(\mathrm{M})$ quotient of $\mathrm{M}_{\mathrm{CAT}}$ divided by $\mathrm{M}_{\mathrm{LIT}}$ and $\mathrm{M}_{\mathrm{RLT}}$ divided by $\mathrm{M}_{\mathrm{RLIT}}$

$\mathrm{R}$ load ratio

$\mathrm{T}_{1} \quad$ temperature in the specimen gauge length

$T_{2}, T_{3}$ temperatures at the specimen shafts

$\Delta \mathrm{R}$ change in electrical resistance

$\Delta \mathrm{T}$ change in temperature

$\varepsilon_{\mathrm{a}, \mathrm{p}} \quad$ plastic strain amplitude

$\sigma_{\mathrm{a}} \quad$ stress amplitude

$\sigma_{\max }$ maximum stress

$\sigma_{\mathrm{f}} \quad$ fatigue strength coefficient

$\sigma_{\mathrm{f}, \mathrm{M}}^{\prime}$ fatigue strength coefficient of generalized Basquin equation

\section{Abbreviations and Subscripts}

calc. calculated

CAT constant amplitude test

exp. experimental

LIT load increase test 
RLIT random load increase test

RLT random load test

start. starting

\section{Materials}

Besides the railway wheel steel SAE 1050 (R7) widely used in high-speed passenger and in freight traffic in Germany, the quenched and tempered $\left(550^{\circ} \mathrm{C}\right.$ for $\left.120 \mathrm{~min}\right)$ steel SAE 4140 (42CrMo4) was investigated. The chemical compositions are given in Tab. 1.

\begin{tabular}{cccccccc}
\hline & $\mathrm{C}$ & $\mathrm{Si}$ & $\mathrm{Mn}$ & $\mathrm{Cr}$ & $\mathrm{Cu}$ & $\mathrm{Mo}$ & $\mathrm{Ni}$ \\
\hline SAE 1050 & 0.53 & 0.32 & 0.75 & 0.26 & 0.04 & 0.01 & 0.11 \\
SAE 4140 & 0.38 & 0.30 & 0.73 & 1.04 & 0.09 & 0.18 & 0.08 \\
\hline
\end{tabular}

Tab. 1: Chemical composition of the wheel steel SAE 1050 and the quenched and tempered steel SAE 4140

SAE 1050 specimens were machined in rolling direction from the rim of industrially heat treated railway wheels $35 \mathrm{~mm}$ below the tread, corresponding to the 'limiting diameter' (15). The gauge length of all specimens was polished to a mean surface roughness of about $0.20 \mu \mathrm{m}$.

As shown in Fig. 1, the microstructure of the wheel steel SAE 1050 (a) is ferritic-perlitic with an average ferrite fraction of 11.2 area- $\%$ and an average cementite lamellae distance of $0.17 \mu \mathrm{m}$. The microstructure of the quenched and tempered steel $\mathrm{SAE} 4140$ (b) is characterized by fine dispersed $\mathrm{Fe}_{3} \mathrm{C}$ carbides.

(a)

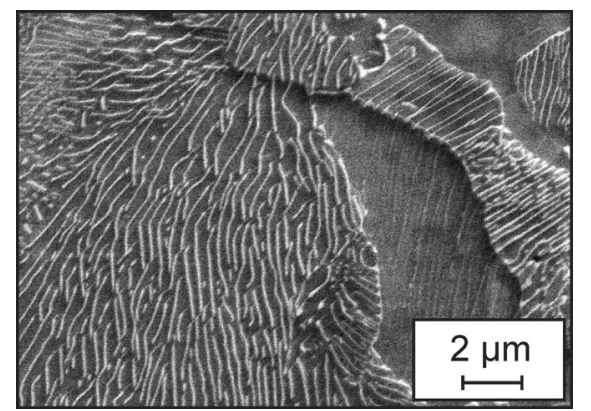

(b)

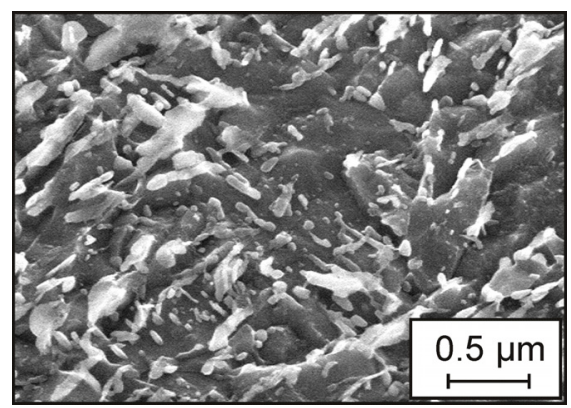

Fig. 1: SEM micrographs of the wheel steel SAE 1050 (a) and the quenched and tempered steel SAE 4140 (b)

Table 2 summarizes the Vickers hardness and selected monotonic properties of the materials investigated.

\begin{tabular}{|c|c|c|c|c|}
\hline & & & SAE 1050 & SAE 4140 \\
\hline Vickers hardness & HV10 & & 257 & 346 \\
\hline Yield strength & $\mathrm{R}_{\mathrm{eS}}, \mathrm{R}_{\mathrm{p} 0.2}$ & [MPa] & 505 & 960 \\
\hline Tensile strength & $\mathrm{R}_{\mathrm{m}}$ & [MPa] & 850 & 1051 \\
\hline Ratio & $\mathrm{R}_{\mathrm{eS}} / \mathrm{R}_{\mathrm{m}}, \mathrm{R}$ & & 0.59 & 0.91 \\
\hline
\end{tabular}

Tab. 2: Vickers hardness and monotonic properties of the wheel steel SAE 1050 and the quenched and tempered steel SAE 4140 


\section{Experimental Setup}

For the measurement of the plastic strain amplitude, determined in mechanical stress-strain hysteresis loops, an extensometer was used. The change in temperature $\Delta \mathrm{T}$ was measured with one thermocouple in the middle of the specimen gauge length $\left(T_{1}\right)$ and two thermocouples $\left(T_{2}\right.$ and $\left.T_{3}\right)$ at the elastically loaded specimen shafts. For electrical resistance measurements a DC-power supply was fixed at both specimen shafts and $\Delta \mathrm{R}$ was measured with two wires spot welded at the transition of the gauge length and the shafts (Fig. 2).

Axial stress-controlled fatigue tests were performed at ambient temperature with a frequency of $\mathrm{f}=5 \mathrm{~Hz}$ on servohydraulic testing systems. In load increase tests (LITs) and constant amplitude tests (CATs) a load ratio of $\mathrm{R}=-1$ and triangular load-time functions were used.
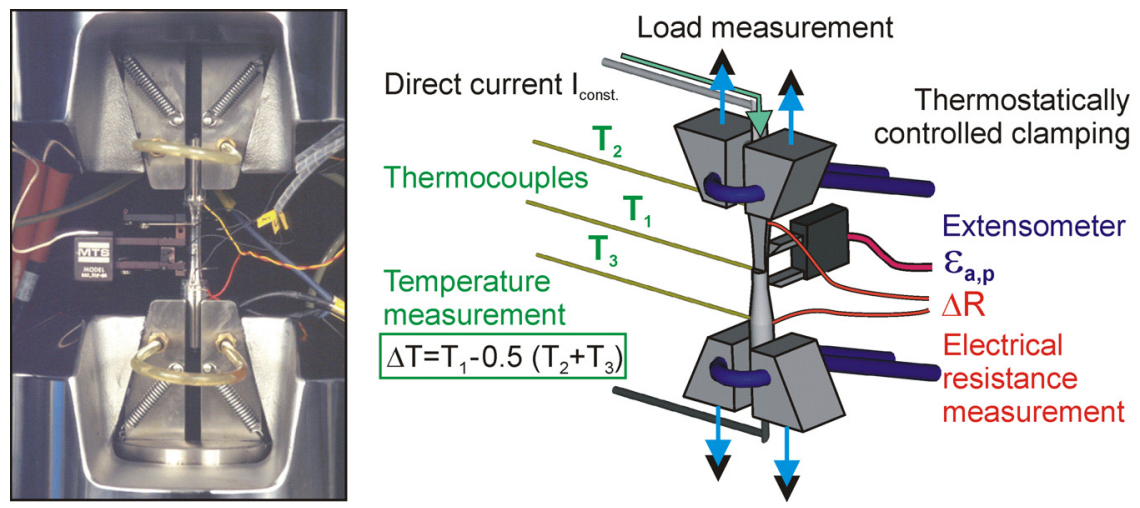

Fig. 2: Experimental setup

For random load increase tests (RLITs) and random load tests (RLTs) a signal as combination of White Noise and Gauss distribution was generated ${ }^{(10)(12)}$ and a new test procedure was applied (Fig. 3). In RLITs the maximum stress $\sigma_{\max }$ of consecutive random sequences was increased in a stepwise manner by $\Delta \sigma_{\max }$, equivalent to the stepwise increase of the stress amplitude $\sigma_{\mathrm{a}}$ by $\Delta \sigma_{\mathrm{a}}$ in load increase tests. In RLTs the maximum stress in all random sequences is identical. Measuring sequences with a stress amplitude $\sigma_{\mathrm{a}}$ of about $60 \%$ of the endurance limit of the investigated metals were periodically inserted in both, random load increase tests and random load tests.

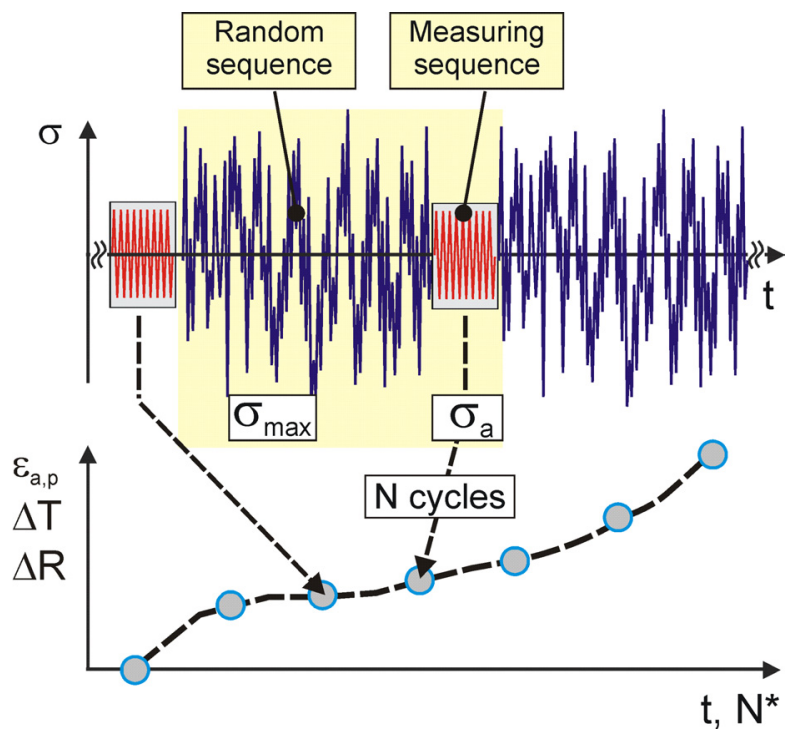

Fig. 3: Test scheme for random load increase tests and random load tests, schematic 
For fatigue assessment under random loading, the average $\varepsilon_{\mathrm{a}, \mathrm{p}}, \Delta \mathrm{T}$ and $\Delta \mathrm{R}$ values of each measuring sequence are plotted as function of the number of cycles $\mathrm{N}^{*}$ in cyclic deformation curves, similar as known from constant amplitude tests. Consequently, the fatigue behavior under random loading can be characterized on the basis of $\varepsilon_{\mathrm{a}, \mathrm{p}} \mathrm{N}^{*}, \Delta \mathrm{T}-\mathrm{N}^{*}$ and $\Delta \mathrm{R}-\mathrm{N}^{*}$ curves. The short constant amplitude sequences with a portion of the load spectra of about $12 \%$ are included in $\mathrm{N}^{*}$. It was proved in random tests with and without measuring sequences that the insertion of the short constant amplitude sequences with $\sigma_{\mathrm{a}} \approx 60 \%$ of the endurance limit of the metals investigated don't cause any additional fatigue damage.

\section{Results}

\subsection{Determination of Woehler (S-N) Curves for Constant Amplitude Loading}

Load increase tests (LITs) allow to estimate the endurance limit of metallic materials with one single specimen, cf. Ref. (2). In Fig. 4 besides the stress amplitude $\sigma_{\mathrm{a}}$, starting at $\sigma_{\mathrm{a} \text {, start. }}=100 \mathrm{MPa}$ with a stepwise increase of $\Delta \sigma_{\mathrm{a}}=20 \mathrm{MPa}$ each $\Delta \mathrm{N}=9 \times 10^{3}$ cycles, the plastic strain amplitude $\varepsilon_{\mathrm{a}, \mathrm{p}}$, the change in temperature $\Delta \mathrm{T}$ and the change in electrical resistance $\Delta \mathrm{R}$ are plotted versus the number of cycles for $\mathrm{N} \geq 0.75 \times 10^{5}$. The $\varepsilon_{\mathrm{a}, \mathrm{p}}, \Delta \mathrm{T}$ and $\Delta \mathrm{R}$ data represent equivalently the actual fatigue state of the wheel steel and result in similar curves. The endurance limit can be estimated by the determination of the transition point from zero values to significantly increasing $\varepsilon_{\mathrm{a}, \mathrm{p}}, \Delta \mathrm{T}$ and $\Delta \mathrm{R}$ values at $\sigma_{\mathrm{a}, \mathrm{LIT}}=300 \mathrm{MPa}$. Failure occurs at $\sigma_{\mathrm{a}}=460 \mathrm{MPa}$.

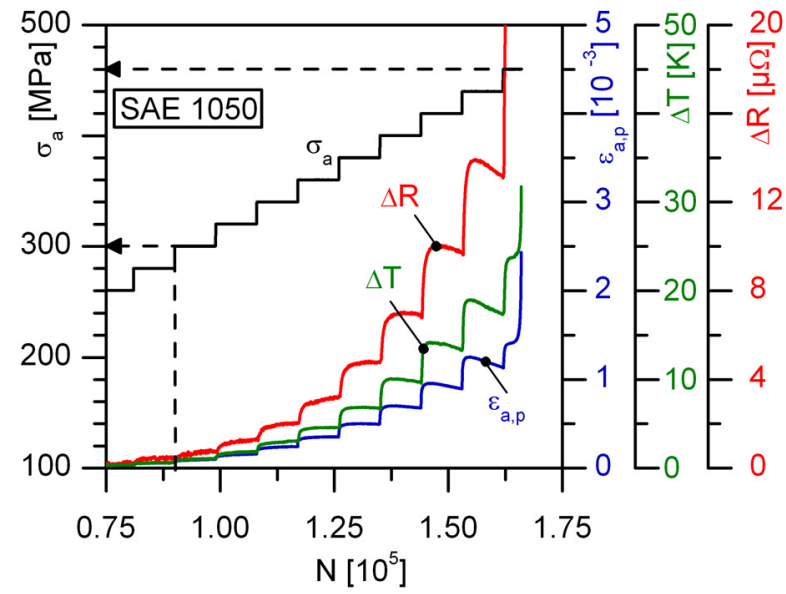

Fig. 4: Development of the plastic strain amplitude and the changes in temperature and resistance in a load increase test, wheel steel SAE 1050

In addition to the LIT in Fig. 4, two constant amplitude tests (CATs) were performed at stress amplitudes of 340 and $420 \mathrm{MPa}$. The stress amplitudes of the CATs were chosen slightly above $\sigma_{\mathrm{a} \text {, LIT }}$ and slightly below the stress amplitude, which leads to failure in the LIT. In Fig. 5 for both CATs the cycle-dependent developments of the plastic strain amplitude and the change in electrical resistance are plotted, leading to similar curves. 


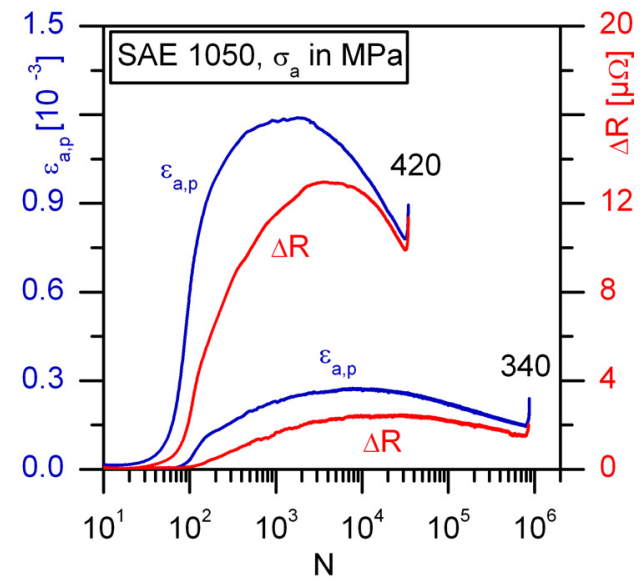

Fig. 5: Cyclic deformation curves of constant amplitude tests, wheel steel SAE 1050

In the following, the calculation of Woehler (S-N) curves according to the lifetime calculation method "PHYBAL" is explained in detail. The power law according to Morrow can be used to describe cyclic stress-strain (CSS) curves, where the stress amplitude $\sigma_{a}$ is plotted versus the plastic strain amplitude $\varepsilon_{\mathrm{a}, \mathrm{p}}$. To include additional quantities like the change in temperature $\Delta \mathrm{T}$ and the change in electrical resistance $\Delta \mathrm{R}$ besides $\varepsilon_{\mathrm{a}, \mathrm{p}}$, the power law can be written in a generalized formulation with the cyclic hardening coefficient $\mathrm{K}_{\mathrm{M}}$ instead of $\mathrm{K}$ ', the cyclic hardening exponent $\mathrm{n}^{\prime}{ }_{\mathrm{M}}$ instead of $\mathrm{n}$ ' and the measured values $\mathrm{M}=\varepsilon_{\mathrm{a}, \mathrm{p}}, \Delta \mathrm{T}$ or $\Delta \mathrm{R}$ instead of $\varepsilon_{\mathrm{a}, \mathrm{p}}$ (Eq. (1)):

$$
\sigma_{\mathrm{a}}=\mathrm{K}^{\prime} \times\left(\varepsilon_{\mathrm{a}, \mathrm{p}}\right)^{\mathrm{n}^{\prime}} \rightarrow \sigma_{\mathrm{a}}=\mathrm{K}_{\mathrm{M}}^{\prime} \times(\mathrm{M})^{\mathrm{n}_{\mathrm{M}}^{\prime}}
$$

Consequently, Eq. (1) can be equivalently used to describe the relation between the stress amplitude $\sigma_{\mathrm{a}}$ and each measured value $M$ for different load levels of a load increase tests as well as for constant amplitude tests at a defined number of cycles, e.g. $10^{4}$. The plot of $\sigma_{\mathrm{a}}$ versus $\Delta \mathrm{T}$ or $\Delta \mathrm{R}$ yields cyclic stress-temperature (CST) or cyclic stress-resistance (CSR) curves.

The $\sigma_{\mathrm{a}}-\mathrm{N}_{\mathrm{f}}$ relation of Woehler curves can be described according to Basquin with the fatigue strength coefficient $\sigma_{\mathrm{f}}^{\prime}$ and the fatigue strength exponent $b$ (Eq. (2)). In the generalized formulation, similar to Eq. (1), the fatigue strength coefficient $\sigma_{\mathrm{f}, \mathrm{M}}$ and the fatigue strength exponent $b_{M}$ are used:

$$
\sigma_{\mathrm{a}}=\sigma_{\mathrm{f}}^{\prime} \times\left(2 \mathrm{~N}_{\mathrm{f}}\right)^{\mathrm{b}} \rightarrow \sigma_{\mathrm{a}}=\sigma_{\mathrm{f}, \mathrm{M}}^{\prime} \times\left(2 \mathrm{~N}_{\mathrm{f}}\right)^{\mathrm{b}_{\mathrm{M}}}
$$

Furthermore, according to Morrow the fatigue strength exponent $b$ (generalized: $b_{M}$ ) can be calculated by means of the cyclic hardening exponent $n$ (generalized: $n_{M}$ ):

$$
\mathrm{b}=\frac{-\mathrm{n}^{\prime}}{5 \mathrm{n}^{\prime}+1} \rightarrow \mathrm{b}_{\mathrm{M}}=\frac{-\mathrm{n}_{\mathrm{M}}^{\prime}}{5 \mathrm{n}_{\mathrm{M}}^{\prime}+1}
$$

With n' ${ }_{M}$ determined from CSS, CST or CSR curves using Eq. (1) and $b_{M}$ calculated according to Eq. (3) as well as with the $\sigma_{\mathrm{a}}-\mathrm{N}_{\mathrm{f}}$ relation of one constant amplitude test, $\sigma_{\mathrm{f}, \mathrm{M}}$ in Eq. (2) can be determined. Consequentially, Woehler curves can be calculated according to Eq. (4), derived from Eq. (2): 


$$
\mathrm{N}_{\mathrm{f}}=0.5 \times\left(\frac{\sigma_{\mathrm{a}}}{\sigma_{\mathrm{f}, \mathrm{M}}^{\prime}}\right)^{\frac{1}{\mathrm{~b}_{\mathrm{M}}}}
$$

It was proved in detail that already fatigue data of only one load increase test (LIT) and two constant amplitude tests (CATs) until $10^{4}$ cycles enable a reliable fatigue life calculation of metals.

Below, the calculation of the Woehler curve for the wheel steel SAE 1050 is illustrated on the basis of the deformation-induced change in electrical resistance $\Delta \mathrm{R}$, but can be done in the same manner using the plastic strain amplitude $\varepsilon_{\mathrm{a}, \mathrm{p}}$ or the change in temperature $\Delta \mathrm{T}$. In Fig. 6 the cyclic stress-resistance (CSR) curve of the LIT (Fig. 4) is shown for average $\Delta \mathrm{R}$ values (O) of the load levels $340 \mathrm{MPa} \leq \sigma_{\mathrm{a}} \leq 420 \mathrm{MPa}$. Besides, for both CATs (Fig. 5) the $\Delta \mathrm{R}$ values at $10^{4}$ cycles $(\nabla)$ are plotted. The $\Delta \mathrm{R}$ values of the CATs at $10^{4}$ cycles are close to the state of maximum cyclic softening (Fig. 5). The $\Delta \mathrm{R}$ values for the load levels 340 and $420 \mathrm{MPa}$ of the LIT are average values. In these average values e.g. smaller values at level beginning (340 $\mathrm{MPa})$ and decreasing values due to cyclic hardening (420 MPa) are considered (Fig. 4). Consequently, in this case the $\Delta \mathrm{R}$ values of the CATs are greater than the average $\Delta \mathrm{R}$ values of the LIT.

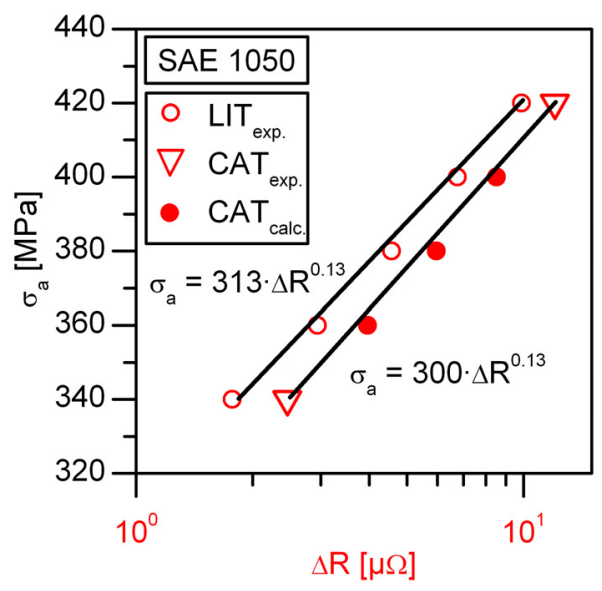

Fig. 6: Morrow curve for a load increase test ( $\left.O \operatorname{LIT}_{\text {exp. }}\right)$, $\Delta \mathrm{R}$ values at $10^{4}$ cycles for two constant amplitude tests $\left(\nabla \mathrm{CAT}_{\text {exp. }}\right)$ and

Morrow curve calculated for constant amplitude loading ( $\mathrm{CAT}_{\text {calc. }}$ ), wheel steel SAE 1050

At first the ratio $\mathrm{Q}(\mathrm{M})$ between the measured values $\mathrm{M}_{\mathrm{CAT}}$ of the two CATs at $10^{4}$ cycles $(\nabla)$ and the measured values $\mathrm{M}_{\text {LIT }}$ of the appropriate load levels of the LIT (O) was determined by $\mathrm{M}_{\mathrm{CAT}}$ divided by $\mathrm{M}_{\text {LIT. }} \mathrm{Q}(\Delta \mathrm{R})$ is 1.39 (1.22) for $\sigma_{\mathrm{a}}=340$ (420) $\mathrm{MPa}$ and for the stress amplitudes in-between linearly interpolated. Then the Morrow curve for constant amplitude loading (๑) was calculated by multiplying all $\Delta \mathrm{R}$ values of the LIT with the corresponding ratio $\mathrm{Q}(\Delta \mathrm{R})$. According to Eq. (1) the calculated $\sigma_{\mathrm{a}}-\Delta \mathrm{R}$ curve for constant amplitude loading can be described by the cyclic hardening coefficient $\mathrm{K}_{\Delta \mathrm{R}}{ }_{\mathrm{R}}=300$ and the cyclic hardening exponent $n^{\prime}{ }_{\Delta R}=0.13$. With the fatigue strength exponent $b_{\Delta R}=-0.08$ (Eq. (3)) and the number of cycles to failure $\mathrm{N}_{\mathrm{f}}=3.45 \times 10^{4}$ for the CAT with $\sigma_{\mathrm{a}}=420 \mathrm{MPa}$, the fatigue strength coefficient $\sigma_{\mathrm{f}, \Delta \mathrm{R}}^{\prime}=1002$ in Eq. (2) is determined. With known material parameters $\sigma_{\mathrm{f}, \Delta \mathrm{R}}$ and $\mathrm{b}_{\Delta \mathrm{R}}$ the fatigue life can be calculated according to Eq. (4).

As mentioned above, the calculation was also done using plastic strain amplitude and change in temperature data of the LIT and the two CATs. As shown in Fig. 7 for the wheel steel SAE 1050, the Woehler curves calculated with "PHYBAL" on the basis of $\varepsilon_{\mathrm{a}, \mathrm{p}}, \Delta \mathrm{T}$ and $\Delta \mathrm{R}$ match excellently with the experimentally determined one $\left(\mathrm{N}_{\mathrm{f} \text { exp. }}\right)$. Furthermore, the 
endurance limit $\sigma_{\mathrm{a}, \text { LIT }}=300 \mathrm{MPa}$ estimated in only one load increase test (Fig. 4) divided by the endurance limit $\sigma_{\mathrm{a}, \mathrm{CAT}}=330 \mathrm{MPa}$ determined in constant amplitude tests until $\mathrm{N}=2 \times 10^{6}$ cycles (Fig. 7) yields a very good accordance factor of $91 \%$.

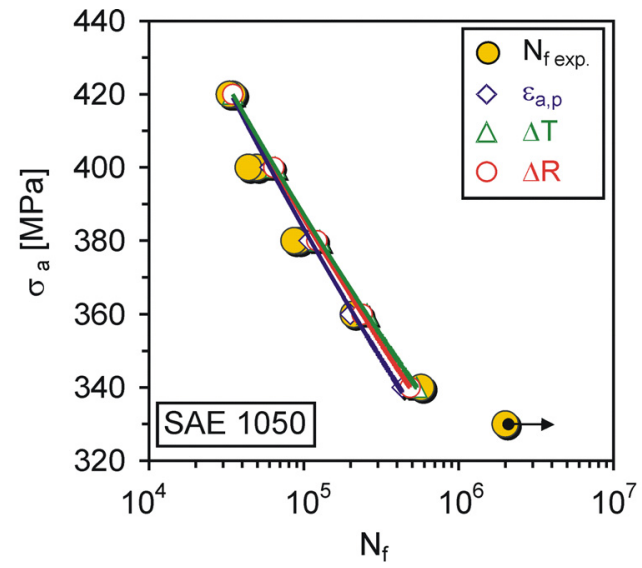

Fig. 7: Comparison of calculated and experimental Woehler (S-N) curves for constant amplitude loading, wheel steel SAE 1050

To underline the high capability of the "PHYBAL" method, in Fig. 8 the excellent accordance of calculated and experimental Woehler curves is additionally plotted for the quenched and tempered steel SAE 4140. The calculated S-N curve based on data of one LIT and two CATs yields the same result as the experimental one $\left(\mathrm{N}_{\mathrm{f} \text { exp. }}\right)$ based on 23 CATs.

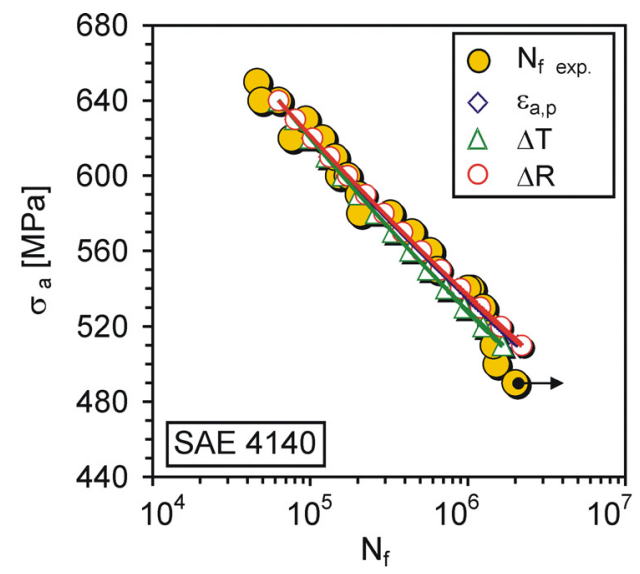

Fig. 8: Comparison of calculated and experimental Woehler (S-N) curves for constant amplitude loading, quenched and tempered steel SAE 4140

It has to be pointed out that the calculation of Woehler curves on the basis of cyclic deformation data taken from one load increase test (LIT) and two constant amplitude tests (CATs) takes a total running time of about two days. Thus, "PHYBAL" saves a lot of time and costs compared to the conventional determination of Woehler curves, requiring about 30 days for constant amplitude tests at $5 \mathrm{~Hz}$ until $2 \times 10^{6}$ cycles. 


\subsection{Determination of Fatigue Life Curves for Random Loading}

According to the test procedure described in Fig. 3, random load increase tests (RLITs) and random load tests (RLTs) were performed with the wheel steel SAE 1050. In RLITs the maximum stress, starting at $\sigma_{\max \text {, start. }}=200 \mathrm{MPa}$ in the first random sequence, was stepwise increased by $\Delta \sigma_{\max }=50 \mathrm{MPa}$ for consecutive random sequences with $\Delta \mathrm{N}^{*}=2.5 \times 10^{3}$ cycles. Short measuring sequences with $\sigma_{\mathrm{a}}=200 \mathrm{MPa}$, i.e. $60 \%$ of the endurance limit, were periodically inserted between random sequences to measure $\varepsilon_{\mathrm{a}, \mathrm{p}}, \Delta \mathrm{T}$ and $\Delta \mathrm{R}$ caused by increasing random loading.

In Fig. 9 besides the course of the maximum stress $\sigma_{\max }$, the load-dependent development of the changes in temperature $\Delta \mathrm{T}$ and resistance $\Delta \mathrm{R}$ are plotted for a RLIT and $\mathrm{N}^{*} \geq 1.5 \times 10^{4}$ cycles. Beneath the stepwise $\sigma_{\max }-\mathrm{N}^{*}$ curve the random spectrum is plotted to visualize that only a few peak loads reach the maximum stress in each load level. An increasing maximum stress leads to increasing temperature and electrical resistance values, measured at $\sigma_{\mathrm{a}}=200 \mathrm{MPa}$ in the subsequent constant amplitude sequence. Obviously, the $\Delta \mathrm{T}$ and $\Delta \mathrm{R}$ data represent the actual fatigue state of the wheel steel in equal manner. The endurance limit can be estimated in the RLIT on the basis of the transition from nearly linearly to exponentially increasing values at $\sigma_{\max , \text { RLIT }}=550 \mathrm{MPa}$. Failure occurs after random loading with $\sigma_{\max }=850 \mathrm{MPa}$.

Analogous to the calculation of Woehler (S-N) curves described in Chapter 4.1, for the calculation of fatigue life curves in addition to one RLIT two RLTs were performed. The maximum stresses 650 and $750 \mathrm{MPa}$ of the RLTs are chosen two $\Delta \sigma_{\max }$ steps above $\sigma_{\max , \text { RLIT }}$ and two $\Delta \sigma_{\max }$ steps below the maximum stress, which leads to failure in the RLIT.

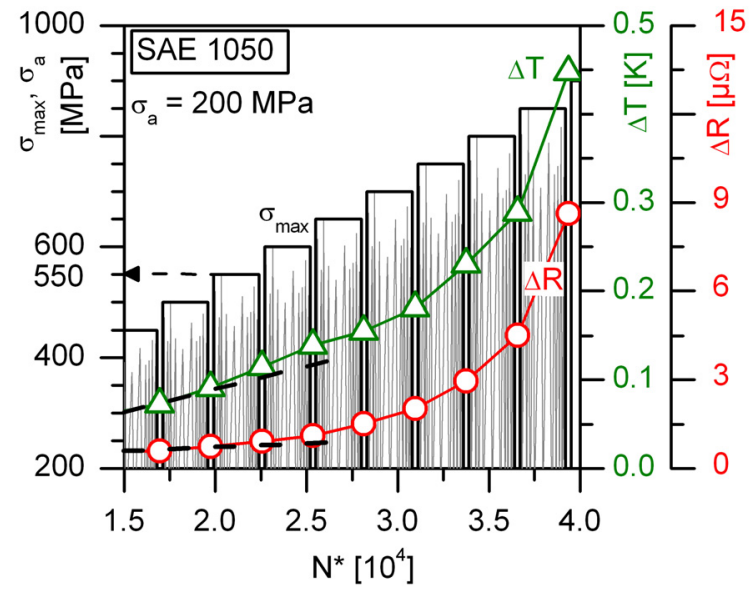

Fig. 9: Development of the changes in temperature and resistance in a random load increase test, wheel steel SAE 1050

The cycle-dependent development of the change in electrical resistance is plotted for both RLTs in Fig. 10. The $\Delta \mathrm{R}-\mathrm{N}^{*}$ curves yield useful information about the fatigue behavior under random loading. Despite their high resolution, the electrical resistance data are characterized by a very small scatter and indicate failure much earlier than the plastic strain amplitude and the change in temperature, cf. Ref. (10). For $\sigma_{\max }=650(750) \mathrm{MPa}$ the transition from linear to exponential slope in the $\Delta \mathrm{R}-\mathrm{N}^{*}$ curves occurs 10 (4) random sequences before final failure. Based on this early indication of fatigue failure by electrical resistance measurements, components could be replaced in sufficient time when a predefined $\Delta \mathrm{R}$ threshold value is reached. Random loading with $\sigma_{\max }=450 \mathrm{MPa}$ was stopped after 200 random sequences without specimen failure. 


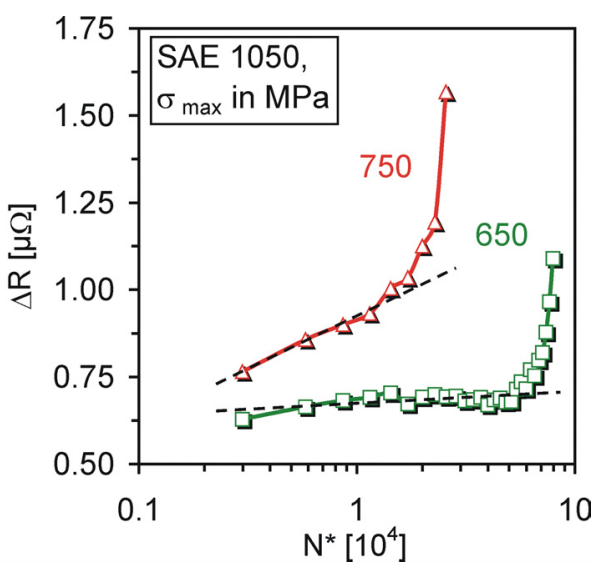

Fig. 10: Cyclic deformation curves of random load tests, wheel steel SAE 1050

The fatigue life calculation method "PHYBAL" was also successfully applied for random loading. Therefore in Eq. (1) to Eq. (3) the stress amplitude $\sigma_{\mathrm{a}}$ has to be substituted for the maximum stress $\sigma_{\max }$ and the number of cycles to failure $\mathrm{N}_{\mathrm{f}}$ for $\mathrm{N}_{\mathrm{f}}{ }^{*}$, respectively.

In Fig. 11 the cyclic stress-resistance (CSR) curve of the RLIT (Fig. 9) is shown for $\Delta \mathrm{R}$ values (O) of the load levels $600 \mathrm{MPa} \leq \sigma_{\max } \leq 800 \mathrm{MPa}$. Besides, for both RLTs (Fig. 10) the $\Delta \mathrm{R}$ values at $10^{4}$ cycles $(\nabla)$ are plotted. For the load levels $\sigma_{\max }=650$ and $750 \mathrm{MPa}$ of the RLIT high $\Delta \mathrm{R}$ values are observed due to proceeding fatigue damage during the previous load levels (Fig. 9). Thus, the $\Delta \mathrm{R}$ data of the RLIT are greater than the $\Delta \mathrm{R}$ data of the RLTs. The ratio $\mathrm{Q}(\Delta \mathrm{R})$ as $\mathrm{M}_{\mathrm{RLT}}$ divided by $\mathrm{M}_{\mathrm{RLIT}}$ was determined for $\sigma_{\max }=650$ and $750 \mathrm{MPa}$. Then the Morrow curve was calculated for random loading ( $\bullet$ ) by multiplying the resistance values of the RLIT with the appropriate ratios $\mathrm{Q}(\Delta \mathrm{R})$.

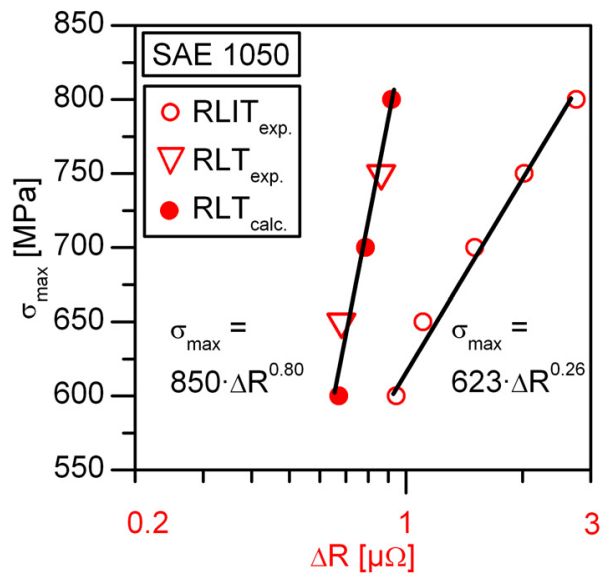

Fig. 11: Morrow curve for a random load increase test ( $O$ RLIT $\left._{\text {exp. }}\right)$, $\Delta \mathrm{R}$ values at $\mathrm{N}^{*}=10^{4}$ cycles for two random load tests $\left(\nabla \mathrm{RLT}_{\text {exp. }}\right)$ and

Morrow curve calculated for random loading $\left(\bullet \mathrm{RLT}_{\text {calc. }}\right)$, wheel steel SAE 1050

The $\sigma_{\max }-\Delta \mathrm{R}$ curve calculated for random loading is characterized by a cyclic hardening coefficient $\mathrm{K}^{\prime}{ }_{\Delta \mathrm{R}}=850$ and a cyclic hardening exponent $\mathrm{n}^{\prime}{ }_{\Delta \mathrm{R}}=0.80$ (Eq. (1)). With the fatigue strength exponent $b_{\Delta R}=-0.16$ (Eq. (3)) and the number of cycles to failure $\mathrm{N}_{\mathrm{f}} *=2.56 \times 10^{4}$ for the RLT with $\sigma_{\max }=750 \mathrm{MPa}$, the fatigue strength coefficient $\sigma_{\mathrm{f}, \Delta \mathrm{R}}^{\prime}=4245$ in Eq. (2) is determined. Finally, Eq. (4) can be used for the calculation of the fatigue life under random loading on the basis of only three fatigue tests.

The fatigue life curves calculated on the basis of temperature $\Delta \mathrm{T}$ and electrical resistance $\Delta \mathrm{R}$ data taken from one random load increase test and two random load tests 
match very well with the experimental fatigue life curve $\left(\mathrm{N}_{\mathrm{f}}{ }^{*}\right.$ exp. $)$, see Fig. 12. There is only a negligible scatter between calculated and experimental fatigue lives.

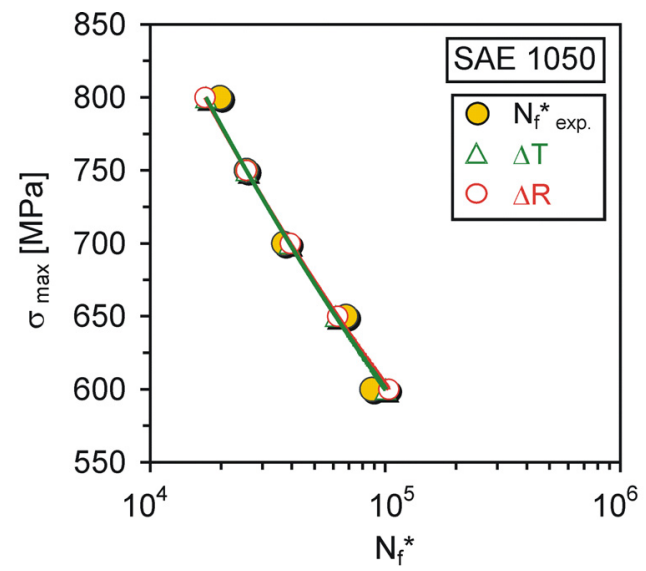

Fig. 12: Comparison of calculated and experimental fatigue life curves for random loading, wheel steel SAE 1050

\section{Conclusions}

Plastic strain amplitude, temperature and electrical resistance measurements can be equivalently used for the characterization of the fatigue behavior and for the calculation of the fatigue life of metals under constant amplitude loading and random loading. Temperature and electrical resistance measurements are proportional to cyclic plastic deformation and provide the opportunity to evaluate the actual fatigue state of components, even under service loading. A new test procedure with short constant amplitude measuring sequences periodically inserted in any kind of random load spectra enables the fatigue assessment under random loading on the basis of cyclic deformation data.

According to the physically based fatigue life calculation method "PHYBAL" one load increase test and two constant amplitude are sufficient for the precise calculation of Woehler (S-N) curves. Load increase tests allow to estimate the endurance limit of metallic materials with one single specimen. The stress amplitudes of the two constant amplitude tests are selected slightly above the endurance limit estimated in the load increase test and slightly below the stress amplitude, which leads to failure in the load increase test. On the basis of plastic strain amplitude, temperature or electrical resistance data measured in the load increase test and in the two constant amplitude tests at $10^{4}$ cycles, the Morrow curve for constant amplitude loading can be calculated. The calculation is also possible with any other fatigue data, e.g. at half lifetime. The fatigue state $10^{4}$ cycles was selected in particular to underline the high capability of the new fatigue life calculation. With the number of cycles to failure of one constant amplitude test, the Woehler curve can be calculated according to generalized Basquin equation in excellent accordance with the experimental one. In the exact same manner fatigue life curves for random loading can be calculated using cyclic deformation data of one random load increase test and of two random load tests at $10^{4}$ cycles. With a total running time of about two days per material, the "PHYBAL" method yields an enormous saving of time and costs compared to the conventional determination of Woehler curves, requiring about 30 days for constant amplitude tests at $5 \mathrm{~Hz}$ until $2 \times 10^{6}$ cycles. In contrast to a calculation of a Woehler curve (fatigue life curve) on the basis of only two constant amplitude tests (random load tests), the new fatigue life calculation method leads to negligible scatter effects, because also information about proceeding fatigue damage caused by previous load levels received from a load increase test (random load increase test) are considered in the "PHYBAL" approach. The determination of S-N 
curves (fatigue life curves) based on only two constant amplitude tests (random load tests) is trivial linear fitting and highly affected by scatter. The fatigue life calculation method "PHYBAL" was also successfully applied on aluminium, magnesium and titanium lightweight alloys.

\section{Acknowledgments}

The support of the German Research Foundation is gratefully acknowledged.

\section{References}

(1) Lukáš, P. and Klesnil, M., Materials Science and Engineering, Vol. 11 (1973), pp. 345-356.

(2) Harig, H. and Frank, E., Wire, Vol. 31 (1981), pp. 227-231.

(3) Fargione, G., Geraci, A., La Rosa, G. and Risitano, A., International Journal of Fatigue, Vol. 24 (2002), pp. 11-19.

(4) Curà, F., Curti, G. and Sesana, R., International Journal of Fatigue, Vol. 27 (2005), pp. 453-459.

(5) Meneghetti, G., International Journal of Fatigue, Vol. 29 (2007), pp. 81-94.

(6) Polák, J., Czechoslovak Journal of Physics, Vol. B 19 (1969), pp. 315-322.

(7) Charrier, J. and Roux, R., Nondestructive Testing and Evaluation, Vol. 6 (1991), pp. 113-124.

(8) Chung, D.D.L., Smart Materials and Structures, Vol. 10 (2001), pp. 624-636.

(9) Sun, B. and Guo, Y., International Journal of Fatigue, Vol. 26 (2004), pp. 457-462.

(10) Walther, F. and Eifler, D., International Journal of Fatigue, Vol. 29 (2007), pp. 1885-1892.

(11) Walther, F. and Eifler, D., Materials Science and Engineering A, Vol. 468-470 (2007), pp. 259-266.

(12) Starke, P., Walther, F. and Eifler, D., International Journal of Fatigue, Vol. 28 (2006), pp. 1028-1036.

(13) Landgraf, R.W., Morrow, J.D. and Endo, T., Journal of Materials, Vol. 4 (1969), pp. 176-188.

(14) Basquin, O.H., The exponential law on endurance tests, Proceedings of ASTM 10 (1910), pp. 625-630.

(15) Walther, F., Eifler, D., Mosler, U. and Martin, U., Zeitschrift für Metallkunde, Vol. 96 (2005), pp. 753-760. 